\title{
Fusarium head blight resistance in European winter wheat: insights from genome-wide transcriptome analysis
}

\author{
Maria Buerstmayr ${ }^{1 *}$, Christian Wagner ${ }^{1 \dagger}$, Tetyana Nosenko ${ }^{2,4}$, Jimmy Omony ${ }^{2,3}$, Barbara Steiner ${ }^{1}$, \\ Thomas Nussbaumer ${ }^{5,6}$, Klaus F. X. Mayer ${ }^{2}$ and Hermann Buerstmayr ${ }^{1}$
}

\begin{abstract}
Background: Fusarium head blight (FHB) is a devastating disease of wheat worldwide. Resistance to FHB is quantitatively controlled by the combined effects of many small to medium effect QTL. Flowering traits, especially the extent of extruded anthers, are strongly associated with FHB resistance.

Results: To characterize the genetic basis of FHB resistance, we generated and analyzed phenotypic and gene expression data on the response to Fusarium graminearum $(F g)$ infection in 96 European winter wheat genotypes, including several lines containing introgressions from the highly resistant Asian cultivar Sumai3. The 96 lines represented a broad range in FHB resistance and were assigned to sub-groups based on their phenotypic FHB severity score. Comparative analyses were conducted to connect sub-group-specific expression profiles in response to Fg infection with FHB resistance level. Collectively, over 12,300 wheat genes were Fusarium responsive. The core set of genes induced in response to $\mathrm{Fg}$ was common across different resistance groups, indicating that the activation of basal defense response mechanisms was largely independent of the resistance level of the wheat line. $\mathrm{Fg}$-induced genes tended to have higher expression levels in more susceptible genotypes. Compared to the more susceptible non-Sumai3 lines, the Sumai3-derivatives demonstrated higher constitutive expression of genes associated with cell wall and plant-type secondary cell wall biogenesis and higher constitutive and Fg-induced expression of genes involved in terpene metabolism. Gene expression analysis of the FHB QTL Qfhs.ifa-5A identified a constitutively expressed gene encoding a stress response NST1-like protein (TraesCS5A01G211300LC) as a candidate gene for FHB resistance. NST1 genes are key regulators of secondary cell wall biosynthesis in anther endothecium cells. Whether the stress response NST1-like gene affects anther extrusion, thereby affecting FHB resistance, needs further investigation.
\end{abstract}

Conclusion: Induced and preexisting cell wall components and terpene metabolites contribute to resistance and limit fungal colonization early on. In contrast, excessive gene expression directs plant defense response towards programmed cell death which favors necrotrophic growth of the Fg pathogen and could thus lead to increased fungal colonization.

\footnotetext{
* Correspondence: maria.buerstmayr@boku.ac.at

†Maria Buerstmayr and Christian Wagner contributed equally to this work. 'University of Natural Resources and Life Sciences, Austria, Department of Agrobiotechnology - IFA Tulln, Institute of Biotechnology in Plant Production, Konrad Lorenz Str 20, Tulln, Austria

Full list of author information is available at the end of the article
}

C The Author(s). 2021 Open Access This article is licensed under a Creative Commons Attribution 4.0 International License, which permits use, sharing, adaptation, distribution and reproduction in any medium or format, as long as you give appropriate credit to the original author(s) and the source, provide a link to the Creative Commons licence, and indicate if changes were made. The images or other third party material in this article are included in the article's Creative Commons licence, unless indicated otherwise in a credit line to the material. If material is not included in the article's Creative Commons licence and your intended use is not permitted by statutory regulation or exceeds the permitted use, you will need to obtain permission directly from the copyright holder. To view a copy of this licence, visit http://creativecommons.org/licenses/by/4.0/. The Creative Commons Public Domain Dedication waiver (http://creativecommons.org/publicdomain/zero/1.0/) applies to the data made available in this article, unless otherwise stated in a credit line to the data. 
Keywords: Triticum aestivum, Fusarium graminearum, Sumai-3, Fhb1, Qfhs.ifa-5A, Cell wall modification, Terpene, NST1, RNA-seq

\section{Background}

Fusarium head blight (FHB), predominately caused by Fusarium graminearum, is one of the most destructive diseases of wheat and small grain cereals worldwide. Yield and quality losses can be devastating and mycotoxins produced by Fusarium pathogens compromise food and feed safety $[1,2]$.

FHB resistance is a quantitative trait, with more than 500 QTL reported in previous studies [3-5]. The Chinese spring wheat cultivar Sumai3 is among the most important and best characterized sources of FHB resistance and is the donor of the two major resistance QTL Fhb1 and Qfhs.ifa-5A [6]. Fhb1 was the first sequenced FHB resistance locus in wheat, yet the casual gene behind the Fhb1 resistance remains unclear. A pore-forming toxin like (PFT) gene [7] and a histidine-rich calcium binding (HRC) protein $[8,9]$ have been proposed as candidate genes for Fhb1. The second resistance locus, Qfhs.ifa- $5 \mathrm{~A}$ was recently fine-mapped into the major effect QTL Qhfs.ifa-5Ac located on the centromere and the minor effect QTL Qfhs.ifa-5AS on the short arm of chromosome 5A [10].

Fusarium fungi colonize and invade wheat heads via open florets during anthesis, a complex and critical reproductive growth stage [11]. The fungi are biotrophic during infection, but once the host cell death is initiated, biotrophic growth is accompanied by necrotrophic intracellular colonization [12]. Production of the trichothecene toxin deoxynivalenol (DON) is specifically induced during colonization and may activate the transition from biotrophy to necrotrophy $[13,14]$.

Plants are constantly challenged by biotic and abiotic stresses. Hence, plants have evolved sophisticated surveillance and defense mechanisms that recognize and rapidly respond to potentially hazardous conditions [15]. Overall, transcriptomic studies have demonstrated that the response of wheat to Fusarium pathogens largely resembles stress defense reactions characteristic of most plant-pathogen interactions $[16,17]$. These plant defense responses include induction of calcium ion influx, generation of reactive oxygen species (ROS), hypersensitive responses, phytohormone-related signaling, induction of pathogenesis-related genes, up-regulation of transcription factor activity, production of antioxidants and antimicrobial substances, detoxification, cell wall modification and cell wall fortification to name a few of the frequently reported defense responses [18-27]. Many of the induced genes showed expression changes in both resistant and susceptible genotypes suggesting, a broad range of basal defense responses [17, 28, 29]. However, genotype-specific gene expression and differences in transcript accumulation between genotypes have also been reported [17, 28, 30].

Plant defense depends on the fine-tuned and coordinated regulation of genes induced upon pathogen attack. It also depends on preexisting constitutive gene expression that provides a significant advantage to the host ahead of the infection. Constitutive defense includes physical and chemical barriers that efficiently impede fungal entry or slow down fungal progress once the fungus has penetrated the plant tissue. Because FHB infection starts inside the floral cavity, mechanisms reducing the likelihood of spores entering the spikelets (e.g. cleistogamous flowering, narrow opening width and short flower opening) increase FHB resistance [31, 32]. Anthers retained within the florets or trapped between the floral brackets are important fungal entry points and the preferred tissue at the onset of FHB infection [3]. Steiner et al. [10] found that Qfhs.ifa-5A has a strong effect on anther extrusion and FHB resistance suggesting a passive, constitutive resistance behind this QTL.

To date, studies on transcriptional response to Fusarium infection or DON infiltration have been restricted to a few wheat genotypes with contrasting resistance [16]. This is the first study that employs a large-scale analysis of gene expression and phenotypic data from 96 genotypes representing the European winter wheat gene pool and experimental lines with Fhb1 and Qfhs-ifa-5A introgressions. The lines span a broad spectrum of FHB resistance from highly resistant to highly susceptible. We aimed to connect transcriptional patterns with FHB resistant and susceptible phenotypes. Previous studies on Fhb1 or Qfhs.ifa-5A-associated resistance focused primarily on transcriptional profiling of near isogenic lines (NILs) [19, 22, 33-37]. Our panel included a small subset of lines carrying the resistance alleles Fhb1 and Qfhs.ifa-5A. This allows for the comparison of expression profiles of resistance alleles in diverse genetic backgrounds and can assist in candidate gene identification.

\section{Experimental procedures \\ Plant material and field experiment for FHB resistance evaluation}

The winter wheat panel consisted of 96 European genotypes, comprising elite cultivars, breeding lines and experimental lines. Fifteen of the experimental genotypes 
are offspring of 'Sumai3' or 'CM-82036' (Sumai3/Thornbird-S) that were phenotypically selected for their high resistance to FHB based on preceding experiments at IFA-Tulln, Austria. The panel was assessed for FHB severity in field tests at IFA Tulln in 2014 and 2015 as described by Michel et al. [38]. The wheat lines covered a broad range in FHB response from highly resistant to highly susceptible (Table S1).

\section{Greenhouse experiment for RNA-sequencing}

Plants were grown under controlled greenhouse conditions as described by Samad-Zamini et al. [35]. Per genotype, two replicates for Fusarium-treatment and one for control (mock-treatment) were planted with ten plants per pot using a randomized complete block design. Individual heads were inoculated at mid-anthesis. Per head, basal florets of six central spikelets were pointinoculated by pipetting $10 \mu \mathrm{l}$ of either a F. graminearum $(F g)$ spore suspension (strain IFA65/66; 50,000 spores/ $\mathrm{mL}$ ) or distilled water (control heads) between palea and lemma to avoid wounding. Following treatments, heads were covered with plastic bags for $24 \mathrm{~h}$ to ensure high humidity for optimal fungal growth. Inoculations were done on consecutive days in February 2015 at approximately 10:00 AM to minimize confounding effects due to circadian gene expression.

Plant tissue of $F g$ and mock-treated spikelets (including rachis, excluding awns) were collected $48 \mathrm{~h}$ after inoculation (hai), immediately shock-frozen in liquid nitrogen and stored at $-80^{\circ} \mathrm{C}$. Fg-treated samples consisted of pools of five individual heads/replication (=pot). Mock-treated control samples consisted of pools of six individual heads/pot. RNA of pooled samples (100 mg) was extracted as described by Samad-Zamini et al. [35].

\section{RNA sequencing, mapping and expression quantification with a dual RNA-seq approach}

Two hundred eighty-eight Illumina HiSeq 2500 strand-specific RNA-seq libraries were sequenced in the $125 \mathrm{bp}$ paired-end mode for the 96 wheat lines (three libraries per line) by GATC Biotech (Konstanz, Germany- now part of Eurofins Scientific). Adapters and low-quality reads were trimmed using Trimmomatic v.0.35 [39]. Data quality was assessed before and after trimming using FastQC [40]. The processed RNA-seq data was aligned using Hisat2 v.2.1.0 [41] to the reference containing the Triticum aestivum reference genome sequence IWGSCv1.0 [42] and the Fhb1 region of the wheat cultivar CM-82036 (KU641029; GI: 1000816923 [36]), whose gene composition at Fhb1 differs from the homologous locus in the Chinese Spring genome (chr3Bfhb1) [43]. The read pairs aligned to exonic regions were summarized per gene using featureCounts [44]. To recover read pairs that aligned to Fhb1 and chr3Bfhb1, one or two to of the best alignments were kept for reads that mapped to multiple loci. Only reads uniquely mapped to a single locus were counted for the remaining non-Fhb1 genes. The resulting raw count matrix was used as an input for the differential gene expression (DGE) analysis. The chr3Bfhb1 locus was identified using sequence similarity search BLASTn of Fhb1 against IWGSCv1.0 using an e-value threshold of $1.0 \mathrm{e}^{-30}$. The number of read-pairs that aligned to $F h b 1$ and chr3Bfhb1 loci were assessed for each wheat line using SAMtools [45]. To test for batch effects, outliers and sample structure, preliminary data analysis was performed using variance stabilizing transformation with the $\mathrm{R}$ package DESeq2 [46].

\section{Differential gene expression (DGE) analyses}

DGE analysis was performed with the R-package DESeq2 [46]. The raw counts were filtered for minimum expression, in which genes with a minimum of 10 library-normalized counts present in at least five libraries were used for further analyses.

In order to compare expression responses to Fusarium infection in wheat lines with different FHB resistance levels, genotypes were grouped based on percentage of infected spikelets (PIS) 26 days after inoculation as follows: resistant (R, PIS $<20 \%$ ), moderate resistant (MR, $20 \%<$ PIS $>65 \%$ ) and susceptible (SUS, PIS $>65 \%$ ). In addition, a highly resistant 'Sumai3-derived' (Sumai3, PIS <6) group was formed comprising only Sumai3 and CM-82036 descendants carrying both, Fhb1 and Qfhs.ifa-5A resistance loci. FHB resistance groups Sumai3, R, MR and SUS comprised 9, 18, 45, and 18 genotypes, respectively (Table $\mathrm{S} 1$ ).

DGE analyses were conducted as follows: i) DGE analyses between $F g$ and mock-treated samples were performed separately for each resistance group, for each genotype and across all genotypes to determine Fusarium responsive genes (FRGs), ii) Pairwise group comparisons were conducted for $F g$ and for mock-treated samples to determine genes differentially expressed (DEGs) between resistance groups, iii) DGE analyses for genotypes contrasting for the resistance allele at Fhb1 and DGE analyses for genotypes contrasting for the resistance allele at Qfhs.ifa-5A were conducted to identify QTL-specific expressed genes.

The thresholds for differential expression was p.adjusted $<0.05$, and $\mid \log _{2}$ expression Fold Change $\left(\log _{2} \mathrm{FC}\right) \mid>1$ for up and down-regulated genes. Functional analysis of annotated DEGs and the downstream gene set enrichment analysis (GSEA) were performed using R-packages GOstats and GSEABase [47]. 


\section{Results}

\section{Gene expression analysis}

Eighty-five percent of the total 7,311,347,144 RNAseq reads (429 Gbp) generated for this project passed the quality trimming and filtering as paired-end reads (3, 112,438,347 read pairs; 4,917,846-24,111,765 read pairs per library with quality score Q30 94\%). Of these reads, $2,936,689,266$ (94.8\%; 4,630,811-22,833,415) pairs per library were aligned to the reference sequences consisting of IWGSCv1.0 genome and Fhb1 locus. In total, 106,582 genes $(70,887$ and 35,695 of high and low confidence, respectively) were expressed. Principal component analysis revealed that gene expression was mainly driven by the $\mathrm{Fg}$ versus mock-treatment, with the first principal component explaining $61 \%$ of the variation (Fig. 1).

\section{Fusarium induced changes in gene expression}

Overall, 90,093 genes passed the minimum expression filtering step and were used for DGE analyses. Collectively, 12,375 genes (14\%) were differentially expressed between $\mathrm{Fg}$ and mock-treatment in at least one analysis (Fig. 2A). Within the Sumai3, R, MR and SUS resistance groups $8741,10,118,10,825$ and 10,741 wheat genes were Fusarium responsive (FR), respectively (Fig. 2B, Table S2), with most genes being up-regulated ( 95\%) (Fig. 2C). Overall, 8040 (65.5\%) genes were induced in all resistance groups. Additionally, 1300 (10.6\%) FRGs were shared by the R, MR and SUS group, but not by the Sumai3 resistance group (Fig. 2D).
Gene ontology (GO) analysis revealed enrichment of the FRGs of individual resistance groups for over 600 biological processes (BP) and over 150 molecular functions (MF) (Table S3). BP terms were largely involved in metabolic process, biological regulation, response to stimulus, cellular process and immune system process. Response to chitin, defense response to fungus, response to endogenous stimulus, regulation of immune system process, respiratory burst involved in defense response, regulation of plant-type hypersensitive response, response to and regulation of hormone levels and signaling were the top enriched GO terms (Fig. 3, Table S3). MFs were enriched for terms associated with catalytic activity, molecular transducer activity and binding. Transmembrane receptor protein serine/threonine kinase activity, peptide receptor activity, protein tyrosine kinase activity, glutathione transferase activity, ubiquitin protein ligase binding, carbohydrate and calmodulin binding were key MF components (Fig. 3, Table S3).

In total, 422 (414 up-regulated, 8 down-regulated) of the FRGs were induced in all genotypes and were considered as general FRGs (GFRGs) (Fig. 2B, Tables S2). Over $25 \%$ of the GFRGs were functionally characterized as protein-like kinase, receptor-like proteins, and receptor-like protein-kinase, indicating general activation of signaling pathways that initiate plant immune and defense responses. Among the most highly upregulated GFRGs were DUF538 family proteins, cytochrome P450, WRKY transcription factors, glycosyltransferases,

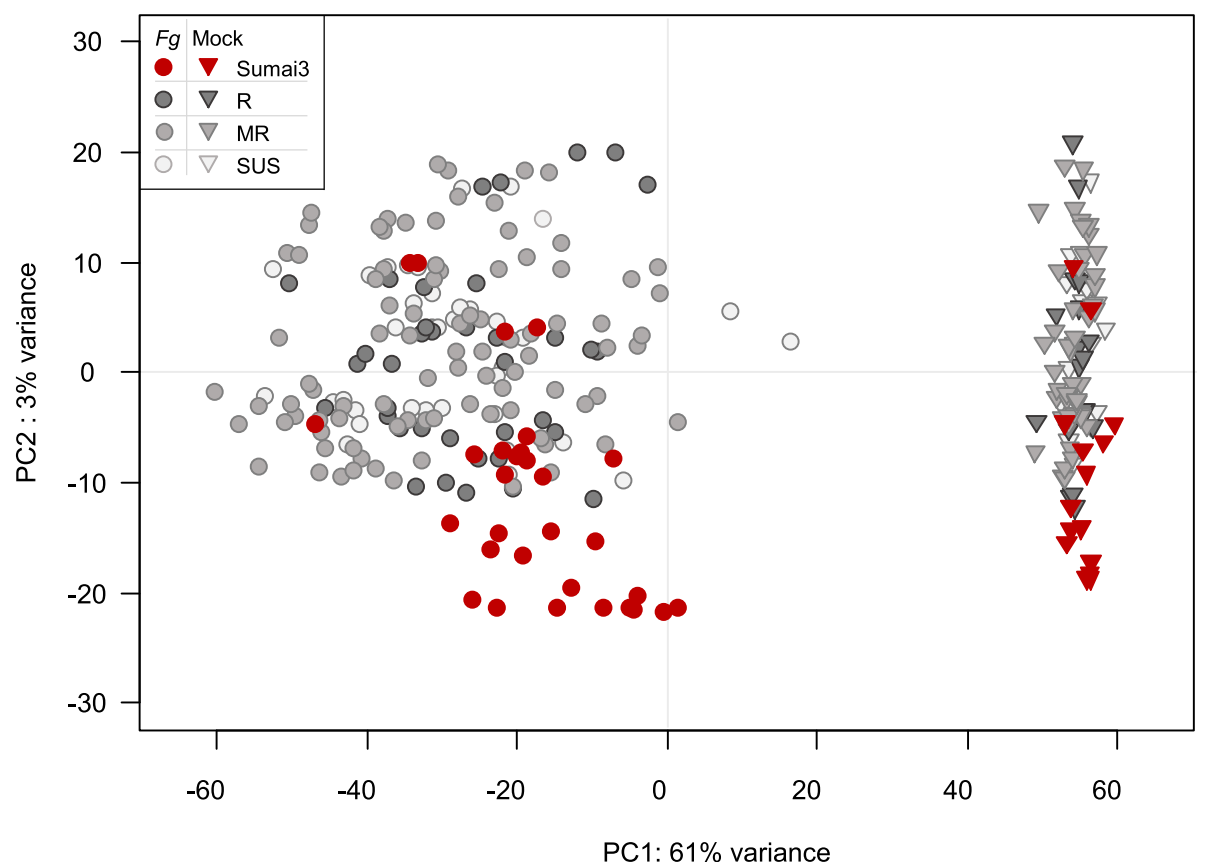

Fig. 1 Principal component analysis of variance-stabilized-transformed read counts. Circles and triangles indicate Fusarium graminearum (Fg) and Mock treatment, respectively. Colors refer to the resistance groups Sumai3, Resistant (R), Moderate Resistant (MR), Susceptible (SUS) 


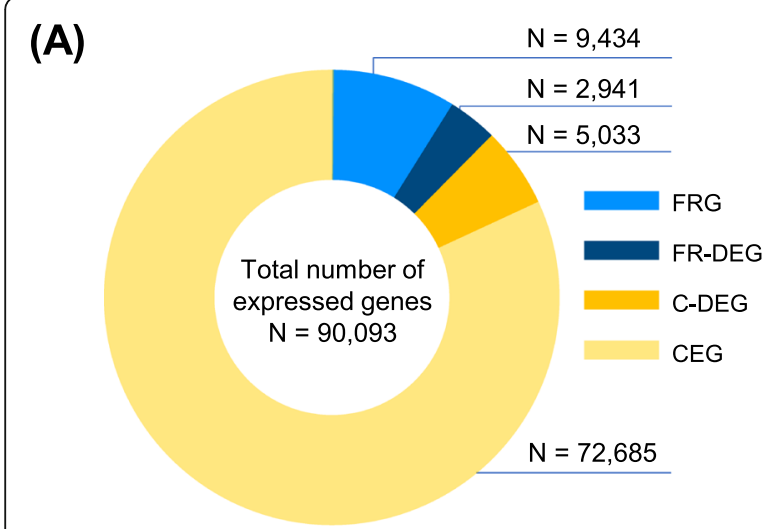

(C)
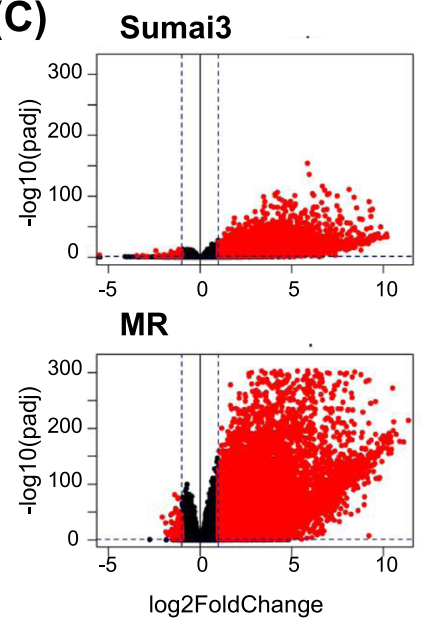

$\mathbf{R}$
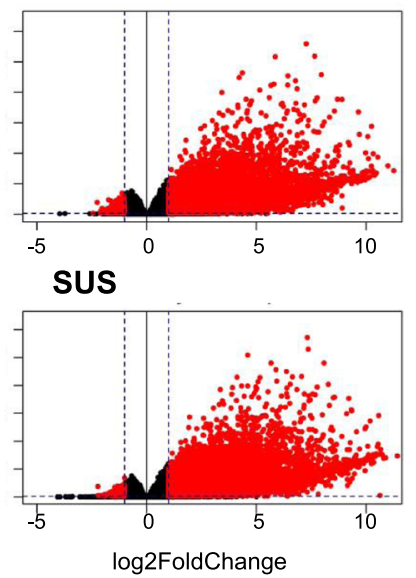

(B)

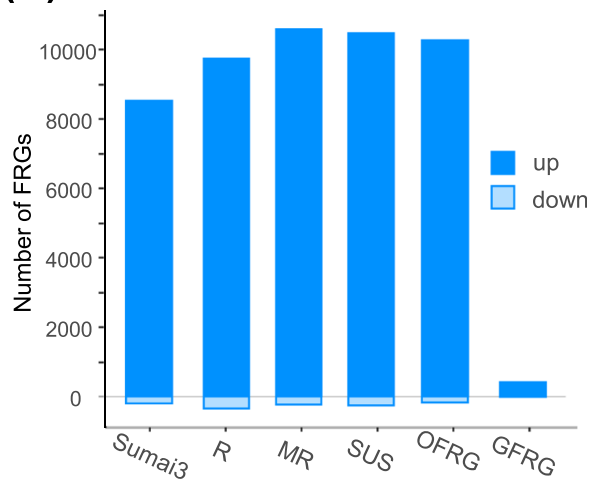

(D)

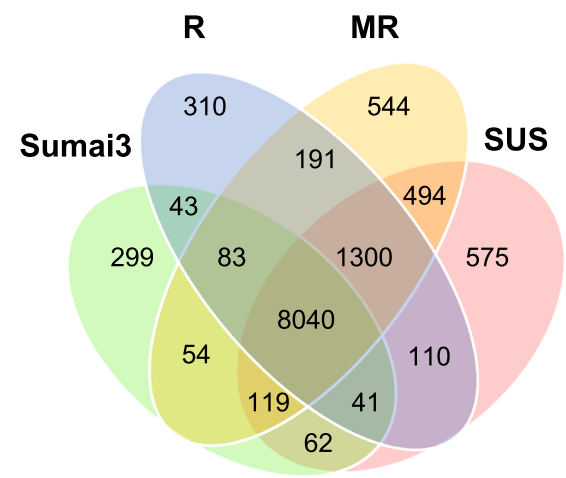

Fig. 2 Summary of differential gene expression analyses. A Total number of expressed genes partitioned into Fusarium responsive genes (FRG) equally expressed across resistance groups, FRGs differentially expressed between resistance groups (FR-DEG), constitutively expressed genes (CEG) and CEGs differentially expressed between resistance groups (C-DEG). B Number of FRGs significantly up or downregulated $48 \mathrm{~h}$ after Fusarium graminearum inoculation for genotypes of resistance groups Sumai3 (Sumai3), Resistant (R), Moderate Resistant (MR) and Susceptible (SUS), and across all genotypes [Overall Fusarium responsive genes (OFRG)], and in each genotype [General Fusarium Responsive Genes (GFRG)]. C Volcano plots showing the distribution of the gene expression fold changes in each resistance group between $\mathrm{Fg}$ and mock treatment. Dots on the left and right sides of horizontal bold line represent downregulated and upregulated genes, respectively. Red dots represent significantly induced genes with $\| \log _{2} \mathrm{FC} \mid>1$ (indicated by dashed horizontal line) and $p$-adjust $\leq 0.05$ (indicated by dashed vertical lines). D Venn diagram showing shared and unique FRGs of resistance groups

receptor-(like)-kinases and pathogenesis-related proteins (Table S2, Table S4).

\section{Differences in gene expression between resistance groups}

Collectively, 7974 and 3589 genes were differentially expressed between the resistance groups after $\mathrm{Fg}$ and mock-treatment, respectively (Table S5). Between groups, most DEGs under mock-treatment (75\%) were also differentially expressed under $F g$ infection (Fig. 4B).

\section{Fusarium responsive DEGs}

Generally, the number of induced genes and the respective transcriptional abundance increased with susceptibility of the genotypes under investigation. The Sumai3 resistance group had 16 to $24 \%$ fewer FRGs than the resistance groups R, MR and the SUS (Fig. 2B). FR gene expression was significantly different between the Sumai3 group and the R, MR and SUS groups for 893, 2476 and 1707 FRGs, respectively. Expression profiles were most similar between the resistance groups $\mathrm{R} \mid \mathrm{MR}$, R|SUS and MR|SUS, amounting to 137, 118 and 18 FRDEGs between groups (Fig. 4A, Table S5).

\section{Constitutive DEGs}

Approximately $86.3 \%(77,718)$ of all expressed genes were constitutively expressed genes (CEG) and showed no differences in expression level between mock and $F g$ treated samples. Overall, 5033 of the CEGs were significantly differentially expressed between resistance groups 


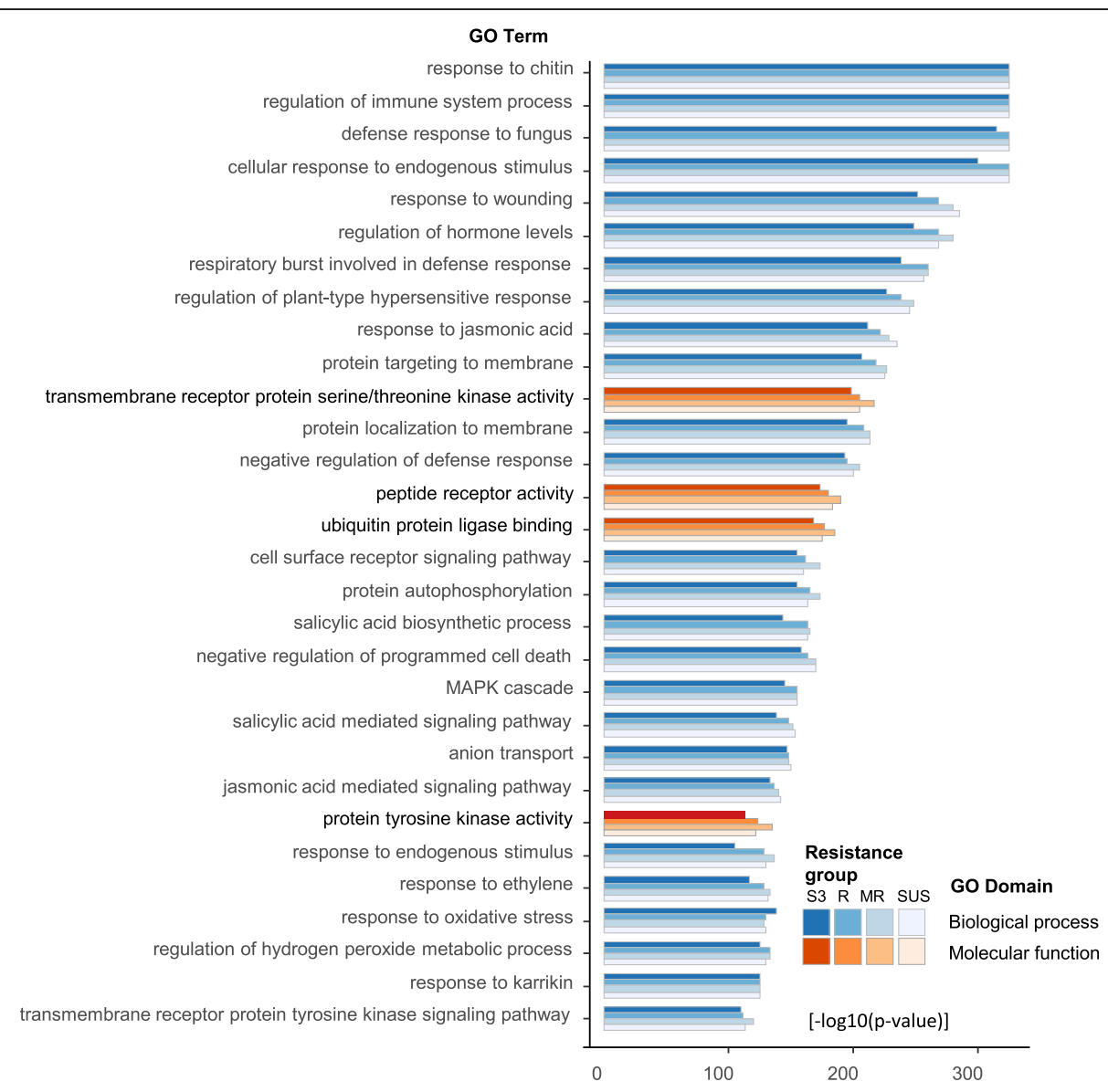

Fig. 3 Top 30 gene ontology (GO) terms enriched for genes significantly upregulated $48 \mathrm{~h}$ after Fusarium graminearum inoculation for individual resistance groups Sumai3 (S3), resistant (R), moderate resistant (MR) and susceptible (SUS). GO terms are ranked according the log 10(p-value) and filtered by odds ratio $\geq 3$ between expected and matched gene counts. For additional information see Table S3

(C-DEGs), thereby potentially conferring passive (constitutive) disease resistance (Fig. 2A). Again, the Sumai3 derivatives were markedly different from all the other groups.

Over $90 \%$ of the FR-DEGs and $70 \%$ of the C-DEGs had significantly higher expression levels in the R, MR or SUS groups relative to the highly resistant Sumai3 derivatives (Fig. 4). Two-thirds of the DEGs between $\mathrm{R} \mid \mathrm{MR}$ and R|SUS had higher expression levels in the more susceptible groups MR and SUS, respectively (Table S5). We grouped genes according to their functional description and compiled summary statistics of the identified FRGs, FR-DEGs and C-DEGs (Table S4). FR-DEGs were dominated by calcium-binding protein, germin-like protein, specific transcription factors (WRKY, ethylene responsive transcription factor, NAC, Myb), and genes involved in detoxification (UDP-glycosyltransferase, glutathione S-transferase, protein detoxification, drug resistance ATP-binding cassette (ABC) transporter) and cell wall fortification (phenylalanine ammonia-lyase, agmatine coumaroyl transferase, blue copper protein, laccase). C-DEGs were overrepresented by NBS-LRR genes, F-box related proteins and transposable elements including retrotransposons and retrovirus related transposons (Table S4, col. F\&G).

\section{GSEA of genes differentially expressed between resistant groups}

To explore the functions of the genes differentially expressed between the resistance groups, we performed GSEA of DEGs obtained by pairwise comparison of groups and joint comparison of 'Sumai3-derived' to 'non-Sumai3-derived' genotypes.

\section{GSEA of FR-DEGs}

Sumai3 derivatives versus European gene-pool

FR-DEGs of the Sumai3 group were overrepresented by up-regulated genes annotated as BP GO terms involved in terpene and phosphate-metabolism and protein phosphorylation (Table S6.2). In contrast, GO term analysis of FRGs highly expressed and enriched in the R, MR and SUS relative to Sumai3 group revealed diverse BPs, with 


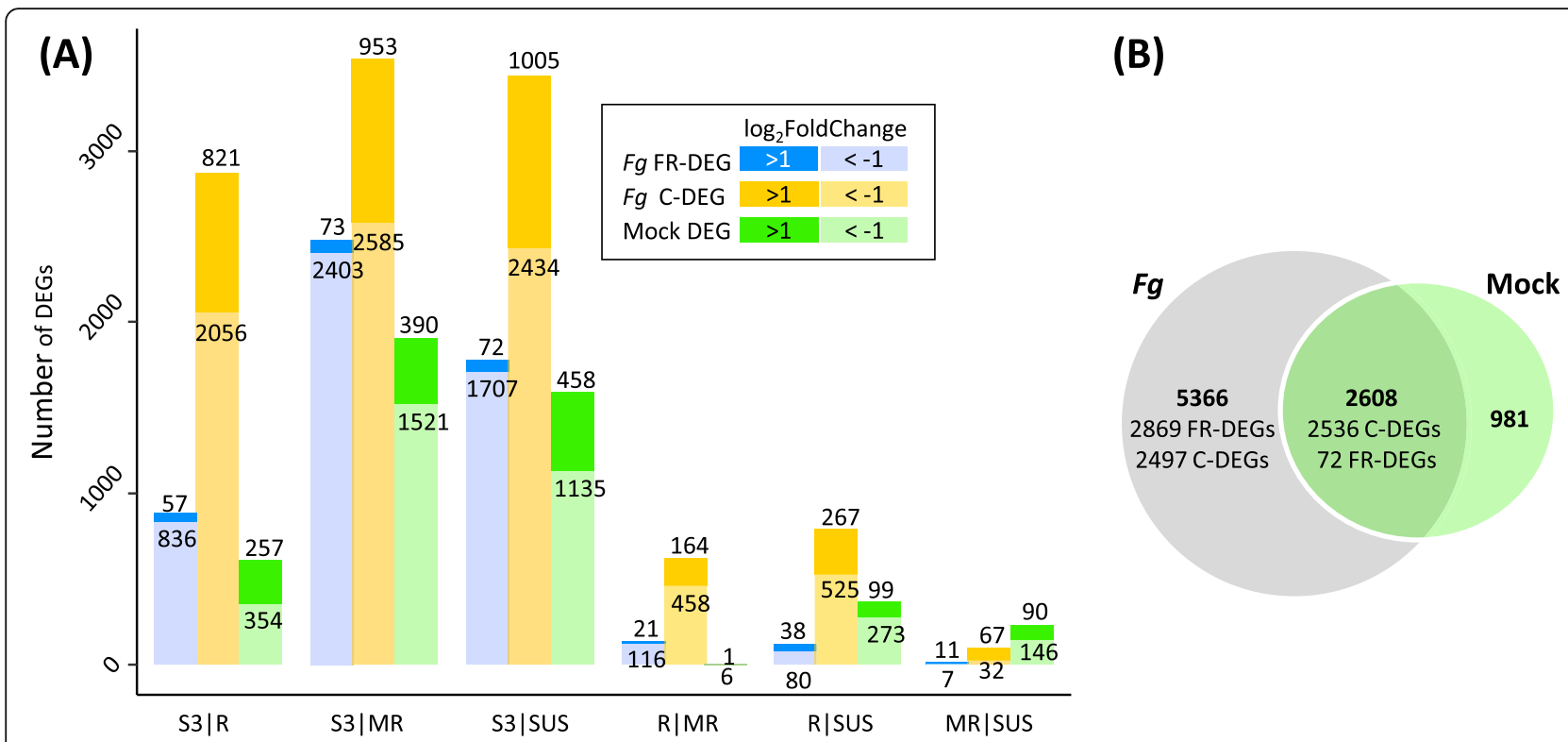

Fig. 4 A Number of genes significantly up- or down regulated ( $\log _{2}$ FoldChange $|>1|$, p-adjust $\leq 0.05$ ) in the pairwise group-comparison between resistance groups Sumai3 (S3), resistant (R), moderate resistant (MR), susceptible (SUS) $48 \mathrm{~h}$ after Fusarium graminearum (Fg) and after Mock treatment (Mock_DEG). Fg treated samples: Fg_FR-DEG: gene significantly differentially expressed both in response to Fg relative to Mock and between compared groups; Fg_C-DEG: gene constitutively differentially expressed between compared groups. For detailed information see Table S5. B Venn diagram showing shared and unique DEGs after Fg and Mock treatment

over 300 sub-categories largely associated with response to stimulus, biological regulation, and cellular-, immune system-, metabolic- and development processes. Response to nitrogen compound, respiratory burst involved in defense response, response to chitin, immune system process, cell communication and regulation of hormone levels were among the most enriched terms (Table S6.2). FR-DEGs involved in UDP-glucosyl and UDP-glucose transferase activity and in peptide and transmembrane signaling receptor activity were among the most enriched MF terms. These genes were highly upregulated in the R, MR and SUS resistance groups compared to the Sumai3 group.

\section{Group comparisons within European gene-pool}

Genes more highly up-regulated by the MR and SUS groups than by the $\mathrm{R}$ group were enriched for catalytic activities and metabolic processes (Table S6.2). The $R$ group demonstrated enrichment for genes involved in anatomical structure development and developmental processes involved in reproduction, whereas the SUS group was overrepresented by GO terms involved in metabolic processes.

\section{GSEA of constitutively expressed C-DEGs}

\section{Sumai3 derivatives versus European gene-pool}

The Sumai3 group was enriched for genes associated with protoxylem development, plant-type secondary cell wall, triterpenoid biosynthesis and glycerophosphate shuttle for C-DEGs after Fg-treatment (Table S6.3, Figure S1). Terpene, terpenoid and hemicellulose metabolic processes and terms associated with cell wall biogenesis were overrepresented after mock-treatment in Sumai3 compared to the non-Sumai3 or SUS groups (Table S6.4). The non-Sumai3 groups were enriched for functional processes contributing to immune and defense response.

\section{Group comparisons within the European gene-pool}

Compared to the SUS group, differently expressed genes in the $\mathrm{R}$ group were enriched and up-regulated for GO terms associated with reproduction and anatomical structure development (anther dehiscence, pollen sperm cell differentiation, cell wall modification involved in abscission) and pectin catabolic processes. C-DEGs upregulated in the SUS and MR groups were more abundant and diverse and were enriched for 26 and 31 functional categories of GO BPs and MFs, respectively (Table S6.3). The most highly enriched BP terms were associated with lipid transport, chromatin organization (regulation of chromatin assembly, regulation of methylationdependent chromatin silencing, histone acetylation), down-regulation of endopeptidase and hydrolase activity, downregulation of proteolysis and protein metabolic process. The most highly enriched MFs were involved with lipid binding, enzyme regulator activity, and pectin esterase-, peptidase- and cysteine-type endopeptidase inhibitor activity. 


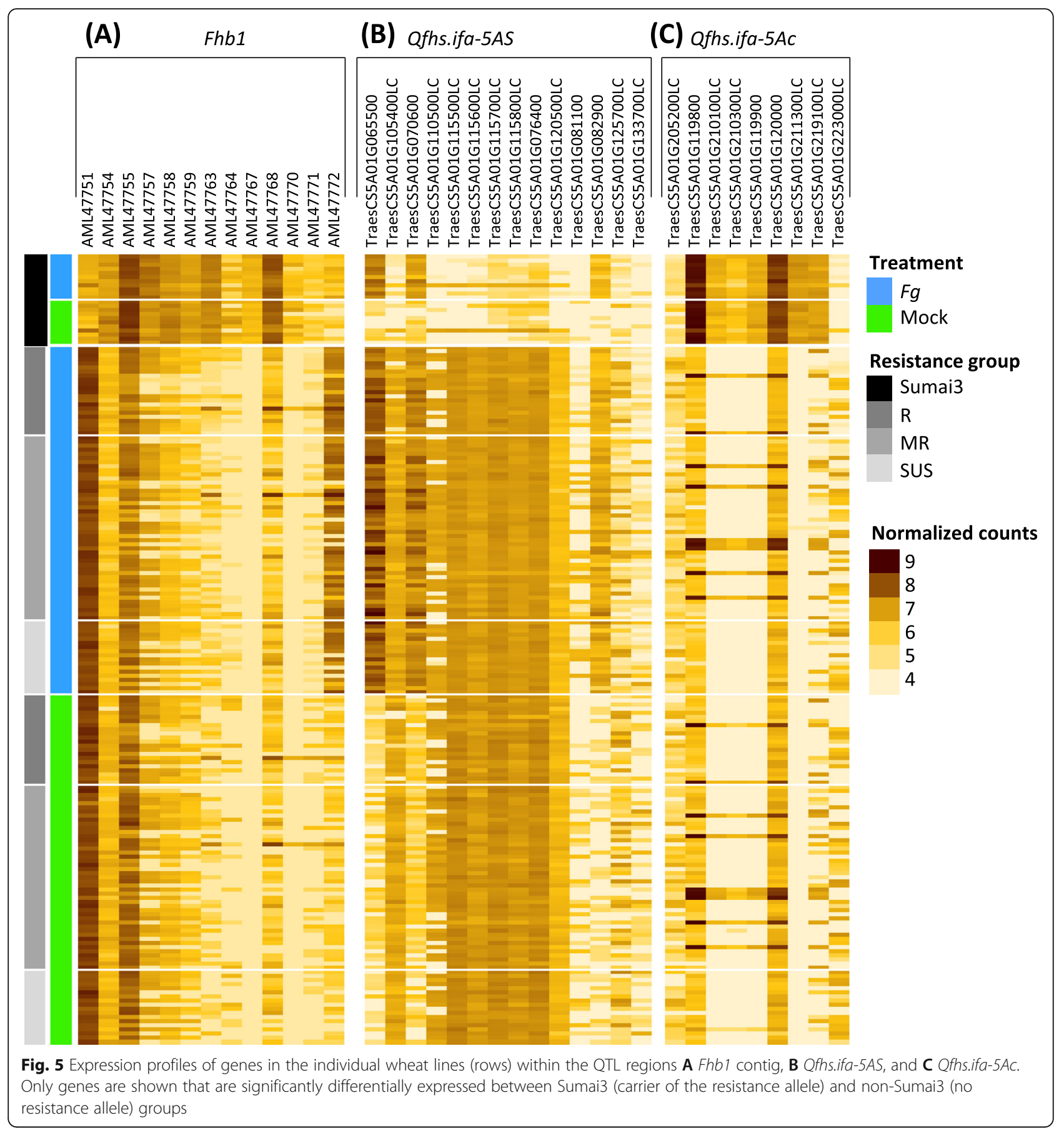

Expression analyses of genes located in the Fhb1, Qfhs.ifa-5AS and Qfhs.ifa-5Ac QTL regions

Marker analyses confirmed the presence of the resistance alleles for either Fhb1 or Qfhs.ifa-5AS and Qfhs.ifa$5 A c$ or for all three QTLs in two, two and nine of the 15 Sumai3 descendent genotypes, respectively (Table S1). Genes located within the QTL intervals were analyzed for differential transcription abundance between treatments and genotypes by contrasting for the respective resistance QTL.
Differentially expressed genes in the Fhb1 QTL interval The Fhb1 QTL interval comprises 28 candidate genes [43], of which 13 revealed significant differential expression between lines contrasting for Fhb1 (Table 1, Fig. 5). One of the genes, a GDSL lipase acylhydrolase (AML47772), was responsive to $F g$ and downregulated in non-Fhb1 carriers. The other 12 candidate genes showed constitutive expression changes with predominantly higher transcript levels in Sumai3-derivatives harboring Fhb1. PFT (AML47770) and HRC 
Table 1 Differentially expressed genes between genotypes contrasting for the resistance allele Fhb1 or Qfhs.ifa-5A

\begin{tabular}{|c|c|c|c|c|}
\hline Gene ID ${ }^{a}$ & $\begin{array}{l}\text { bp position } \\
\text { start }\end{array}$ & Human-Readable-Description & $\begin{array}{l}\text { Allele }^{b} \\
\text { Log }_{2} \text { FC }\end{array}$ & $\begin{array}{l}\text { Treatm } \\
\log _{2} F C\end{array}$ \\
\hline \multicolumn{5}{|l|}{ Fhb1 } \\
\hline AML47751 & $8,140,000$ & Uncharacterized Protein & -3.4 & \\
\hline AML47754 & $8,200,000$ & Glycosyltransferase HGA-like & 2 & \\
\hline AML47755 & $8,220,000$ & Leucyl-tRNA synthase & 1.3 & \\
\hline AML47757 & $8,260,000$ & Alanyl-tRNA synthase & 2 & \\
\hline AML47758 & $8,280,000$ & Uncharacterized Protein & 2.7 & \\
\hline AML47759 & $8,300,000$ & PAP fibrilling domain containing protein & 3 & \\
\hline AML47763 & $8,360,000$ & Oxidoreductase NAD-binding domain & 4.1 & \\
\hline AML47764 & $8,380,000$ & Terpene synthase & 3.3 & \\
\hline AML47767 & $8,440,000$ & Terpene synthase & 5.6 & \\
\hline AML47768 & $8,460,000$ & Histidine-rich calcium-binding-protein gene & 3.3 & \\
\hline AML47770 & $8,500,000$ & Agglutinin /Pore-forming toxin-like gene (PFT) & 4.4 & \\
\hline AML47771 & $8,520,000$ & E3 ubiquitin-protein ligase & 1.4 & \\
\hline AML47772 & $8,540,000$ & GDSL Lipase acylhydrolase & -2.9 & 4.6 \\
\hline \multicolumn{5}{|l|}{ Qfhs.ifa-5AS } \\
\hline TraesCS5A01G065500 & $71,397,157$ & Glycosyltransferase & -1.3 & 6.4 \\
\hline TraesCS5A01G105400LC & $77,338,937$ & Retrovirus-related Pol polyprotein from transposon TNT 1-94 & -3.9 & \\
\hline TraesCS5A01G070600 & $79,152,530$ & Zinc finger protein, putative & -1 & 4.4 \\
\hline TraesCS5A01G110500LC & $85,151,081$ & Penicillin-insensitive murein endopeptidase & -3.5 & \\
\hline TraesCS5A01G115500LC & $92,180,537$ & Transposon Ty3-G Gag-Pol polyprotein & -4 & \\
\hline TraesCS5A01G115600LC & $92,181,290$ & Transposon Ty3-G Gag-Pol polyprotein & -3.7 & \\
\hline TraesCS5A01G115700LC & $92,182,337$ & Pol polyprotein & -3.7 & \\
\hline TraesCS5A01G115800LC & $92,183,426$ & Ty3-gypsy retrotransposon protein & -3.1 & \\
\hline TraesCS5A01G076400 & $92,184,572$ & Retrotransposon protein, putative, unclassified & -3.2 & \\
\hline TraesCS5A01G120500LC & $103,107,652$ & NADPH--cytochrome P450 reductase & -3.4 & \\
\hline TraesCS5A01G081100 & $104,147,359$ & cation/H+ exchanger 18 & -3.2 & \\
\hline TraesCS5A01G082900 & $108,577,776$ & Receptor-like protein kinase & -1.1 & 4.8 \\
\hline TraesCS5A01G125700LC & $109,629,216$ & Large proline-rich protein BAG6 & -2.8 & \\
\hline TraesCS5A01G133700LC & $119,060,876$ & $\begin{array}{l}\text { Zinc finger (CCCH-type) family protein / RNA recognition motif } \\
\text { (RRM)-containing protein }\end{array}$ & -2.6 & \\
\hline \multicolumn{5}{|l|}{ Qfhs.ifa-5Ac } \\
\hline TraesCS5A01G205200LC & $246,821,246$ & Retrovirus-related Pol polyprotein from transposon TNT 1-94 & -1.5 & \\
\hline TraesCS5A01G119800 & $253,592,929$ & $3^{\prime}\left(2^{\prime}\right), 5^{\prime}$-bisphosphate nucleotidase 1 & 3 & \\
\hline TraesCS5A01G210100LC & $253,593,703$ & Transposon Ty3-G Gag-Pol polyprotein & 3.2 & \\
\hline TraesCS5A01G210300LC & $253,595,868$ & Gag-pol polyprotein & 3 & \\
\hline TraesCS5A01G119900 & $253,596,702$ & Transposon Ty3-I Gag-Pol polyprotein & 3.2 & \\
\hline TraesCS5A01G120000 & $253,604,999$ & Pyruvate dehydrogenase E1 component alpha subunit & 2.4 & \\
\hline TraesCS5A01G211300LC & $257,282,460$ & Stress response NST1-like protein & 7.3 & \\
\hline TraesCS5A01G219100LC & $268,595,903$ & Protein FAR1-RELATED SEQUENCE 3 & 2.5 & \\
\hline TraesCS5A01G223000LC & $274,993,878$ & $\begin{array}{l}\text { Bifunctional glutamine synthetase adenylyltransferase/adenylyl-removing } \\
\text { enzyme }\end{array}$ & -3.6 & \\
\hline
\end{tabular}

${ }^{a}$ Only genes located within the QTL intervals of Fhb1, Qfhs.ifa-5AS and Qfhs.ifa- $5 A$ c and $p$-adjust $\leq 0.05\left|\log _{2} \mathrm{FC}\right|>1$ are listed ${ }^{b}$ Positive $\log _{2} \mathrm{FC}$ indicate higher gene expression in lines carrying the resistance allele

'Treatment, positive $\log _{2} \mathrm{FC}$ indicate higher gene expression in $\mathrm{Fg}$ inoculation samples compared to mock-treatment 
(AML47768), previously reported to solely confer resistance to fungal spreading [7-9] showed higher, treatment-independent expression patterns in 'Fhb1 genotypes'. The highest and most distinct transcript abundance difference between Fhb1 and non-Fhb1 carriers was observed for a Terpene synthase (AML47767) with exclusive expression in 'Fhb1 genotypes'.

\section{Differentially expressed genes in the Qfhs.ifa-5A QTL interval}

Within the Qfhs.ifa-5AS (70.7-119.9 Mbp) and Qfhs.ifa-5Ac (245.9-290.0 Mbp) regions, 216 and 108 genes were expressed, respectively. Fourteen genes within the Qfhs.ifa-5AS and nine genes within the Qfhs.ifa-5Ac interval were differentially expressed between groups contrasting for the resistance allele (Table 1, Fig. 5). Three genes within the Qfhs.ifa-5AS region, characterized as a glycosyltransferase (TraesCS5A01G065500), a zinc finger protein (TraesCS5A01G070600) and a receptor-like protein kinase (TraesCS5A01G082900), were $F g$-induced, and were more highly up-regulated in the non-Sumai3 group. All remaining DEGs were constitutively differentially expressed. More than half of the DEGs comprised transposon-, retrotransposon-, or retrovirus-related proteins. DEGs within the Qfhs.ifa-5AS interval had higher expression levels in the group lacking the resistance allele. In contrast, higher transcript abundance was associated with the presence of the resistance allele for the centromeric QTL Qfhs.ifa$5 A c$. Only the two genes flanking the Qfhs.ifa-5Ac region had higher expression levels in the non-Sumai3 derived lines. The highest expression ratio $\left(\log _{2} \mathrm{FC}=\right.$ 7.3) was observed for the stress response NST1-like protein (TraesCS5A01G211300LC) located within the Qfhs.ifa-5Ac interval at $257,282,460 \mathrm{bp}$, next to the centromere. TraesCS5A01G211300LC was constitutively expressed in all lines containing the Sumai3 allele and not expressed in lines lacking the resistant allele.

\section{Discussion}

We analyzed 96 genotypes, including 15 lines with Sumai3 in their pedigree and 81 European cultivars and breeding lines with a broad variation in FHB resistance. We sampled probes for RNAseq analyses 48 hai - a time point at which the majority of the transcripts are induced by the pathogen and is thus highly informative for expression analysis [22, 48]. At around 48 hai the biotrophic lifestyle of the $F g$ pathogen at the advancing hyphal front is already complemented by a necrotrophic lifestyle feeding on dead tissues [12, 27]. This joint action of both lifestyles requires a tailored and coordinated host defense strategy, as some host defense responses against biotrophs, e.g., programmed cell death (PCD), confer susceptibility to necrotrophs [49].

\section{Fg-induced transcriptional reprogramming}

$\mathrm{Fg}$ inoculation initiated an extensive transcriptional reprogramming suggesting a highly complex hostpathogen interaction. Over 12,300 FRGs were identified, most of which were up-regulated (Fig. 2A). Around twothirds of the FRGs were induced in all resistance groups showing that resistant and susceptible genotypes activated similar defense response mechanisms (Fig. 2B). However, approximately $25 \%$ of the FRGs differing in expression between resistance groups demonstrated an association between higher expression and increased susceptibility. This result corroborates with Pan et al. [28], Biselli et al. [26], and Wang et al. [17], in which the majority of the $\mathrm{Fg}$-induced genes were shared by all wheat genotypes, with higher expression levels typically found in more susceptible lines. Consistent with earlier transcriptional studies, key components of Fusarium response fell into categories and pathways associated with defense responses, such as increased calcium influx, bursts of intracellular ROS, activation of transcription factors, regulation of immune system process, regulation of plant-type hypersensitive response, response to and regulation of hormone levels, accumulation of pathogenesis-related proteins, proteins involved in detoxification, cell wall reinforcement and lignin biosynthesis $[16,17,21,27,28]$.

\section{Differences in gene expression between resistance groups}

Aiming to identify expression patterns that discriminate genotypes according to their resistance level, we conducted pairwise group comparisons. DGE analysis between Sumai3 and the non-Sumai3 groups R, MR, SUS yielded ten and five times more induced FR-DEGs and constitutive C-DEGs, respectively, than group comparisons between R|MR and R|SUS (Fig. 4A). Members of the resistance group Sumai3 are closely related European genotypes with Sumai3 introgressions, while the nonSumai3 genotypes represent diverse European cultivars and breeding lines which were grouped based on resistance to FHB only (Table S1). The non-Sumai3 groups are not only more genetically different from the Sumai3 group, but they also have a broader genetic and phenotypic within-group variance. Response mechanisms among group members may thus be more diverse. As such, response signals found in one or few lines may remain undetected by statistical analysis, leading to the lower number of DEGs found between the R, MR and SUS resistance groups in comparison to those between 
the Sumai3 group and the R, MR or SUS groups (Fig. 4A).

\section{Pathogen recognition - the first player in the pathogen- host interaction}

Receptor-like kinases (RLKs) and nucleotide-binding leucine-rich repeat (NLRs) gene families play crucial roles in pathogen recognition and represent the first layer in downstream activation of plant defense mechanisms [50-52]. RLKs and NLRs were the largest group of $\mathrm{Fg}$ induced genes and the majority of these genes were equally induced across resistance groups (Tables S2, S4). About a quarter of the RLKs/NLRs were exclusively induced in the non-Sumai3 groups. RLKs/NLRs that were differentially expressed between groups showed higher expression levels in the more susceptible groups. This suggests, that in the more resistant lines, particularly in the Sumai3 lines, pathogen recognition may have already occurred before 48 hai, or constitutive resistance mechanisms against pathogen infection led to reduced induction of RLKs/NLRs. The pattern of moderate response associated with resistance and an excessive response associated with susceptibility was observed in most of the downstream activated defense reactions and may be a direct consequence of enhanced RLK/NLR activity in the more susceptible genotypes.

\section{Downstream activation of plant defense mechanism}

$\mathrm{Ca}^{2+}$ and reactive oxygen species (ROS) as signatures of initial direct plant defense response

Calcium signaling: Calcium $\left(\mathrm{Ca}^{2+}\right)$ is a universal second messenger involved in virtually all biotic and abiotic stress responses. Upon perception of stress signals by the membrane receptors $\mathrm{Ca}^{2+}$ influx will be induced within seconds. This transient elevated cytosolic $\mathrm{Ca}^{2+}$ concentration activates calmodulin and $\mathrm{Ca}^{2+}$ dependent protein kinases, nitric oxide and ROS that affect the function of many genes including hormone signaling and transcription factors, which control stress regulated genes [53-55]. We identified over 200 genes with $\mathrm{Ca}^{2+}$ binding domains and calmodulin-like protein families upregulated after $\mathrm{Fg}$ treatment (Table S2 col. AH, Table S4 col. AA). These genes may be critical for adequate defense response, since their upregulation is among the earliest events during the $F g$-host interaction [27].

ROS signaling: ROS, which are partially reduced or activated derivatives of molecular oxygen, are rapidly produced and accumulated in the early phase of the pathogen-host interaction leading to the ROS-mediated oxidative burst [56]. ROS signaling is, amongst others, implicated in pathogen defense, plant hormone response, and systemic acquired resistance when kept in balance, while excess ROS is toxic to plant cells causing cell death [57-59]. Although PCD is a good strategy to ward off biotrophic pathogens, it increases susceptibility once $\mathrm{Fg}$ has switched to the necrotrophic lifestyle. ROS accumulation needs to be counterbalanced by antioxidants to maintain redox homeostasis [60]. Khaledi et al. [61] suggest that a rapid induction of ROS in combination with a rapid induction of antioxidant enzyme activity increases resistance against FHB. We found an activation of 217 predominately upregulated enzymatic antioxidant genes among which 185 were glutathione-Stransferases (GSTs) (Table S2 col. AI, Table S4 col. AE). Per resistance group, 31-40 GSTs were among the top $10 \%$ of genes with the highest fold change in expression after $\mathrm{Fg}$ treatment. An induction of numerous GSTs following Fg treatment was observed by Pan et al. [28] and in accordance to our results GSTs were up-regulated in FHB resistant and susceptible genotypes. GSTs are antioxidants, which help to limit PCD [62, 63], and participate in DON detoxification by the formation of DONglutathione conjugates [20,64]. GSEA analysis revealed 'Respiratory burst involved in defense response' as one of the most highly enriched GO terms in all resistance groups (Fig. 4) and underscores the general importance of oxidative burst in $\mathrm{Fg}$ defense response. Genes contributing to ROS and PCD were more highly upregulated and enriched in non-Sumai3 genotypes relative to Sumai3 lines (Tables S6.1). Since lower levels of early defense responses (RLK/NLR, $\mathrm{Ca}^{2+}$, ROS) are associated with increased FHB resistance we assume that the fate of the $F g$-host interaction will be shaped at or before the onset of the infection and likely depends on constitutive defense mechanisms. The idea that constitutive gene expression may be critical for triggering adequate defense responses is furthermore supported by the few isolated FHB resistance genes. All three cloned FHB resistance genes are constitutively expressed and related to early defense response, with $F h b 1$ encoding a putative histidine-rich calcium-binding protein [8], $F h b 7$ encoding a glutathione S-transferase [65] and QFhb.mgb-2A predicted to encode a wall-associated receptor-like kinase [66].

\section{Host defense responses to limit Fusarium spread Mycotoxin detoxification and cell wall modifications as important components for impeding fungal spread}

Host responses to mycotoxins accumulation: Members of the $\mathrm{Fg}$ species complex produce trichothecene type B toxins that are secreted from the fungal hyphae tip [67]. These mycotoxins are virulence factors that determine the aggressiveness of the Fusarium pathogen and are essential for fungal penetration of the rachis and further spread within the wheat spike [13]. DON triggers ROS production and - depending on the level of ROS accumulation - initiates PCD promoting necrotrophic fungal growth and disease development [14]. Plants can reduce 
DON toxicity through chemical modification into less toxic DON-3-glucoside by uridine-diphosphate glycosyltransferases (UGTs) or the formation of DONglutathione conjugates by GSTs and through toxin efflux by $A B C$ transporters [36, 64, 68-71]. In our study, 51 UGTs, 179 GSTs and 119 ABC transporters were upregulated after $\mathrm{Fg}$ treatment (Table S2 col. AM). The majority of these genes (80\%) were upregulated in all resistance groups with equal or lower levels of gene expression in Sumai3 compared to the non-Sumai3 groups. Differences in gene expression were minimal between the groups R, MR and SUS despite distinct resistance levels, showing that detoxification is an important defense response but has limited power to fully compensate for the higher DON accumulation in the more susceptible groups.

Induced cell wall modifications and constitutive differences in cell wall components affect defense response: Gunnaiah and Kushalappa [72] and Gunnaiah et al. [73] found cell wall thickening together with the antimicrobial and antioxidant properties of induced phenylpropanoid and flavonoid metabolites as the main resistance mechanisms of the Sumai3 cultivar. $F g$ inoculation increased lignin and hemicellulose signals in Sumai3, while signals related to oxidative stress were present in the susceptible cultivar only [74]. Kang and Buchenauer [75] likewise observed that lignin accumulated faster and more intensely in inoculated wheat spikes of resistant cultivars. They concluded, that the combination of cell wall thickness, cell wall composition and lignification determine host resistance to fungal spread within the spike. Our data suggest a general importance of cell wall thickness and lignification, since GO terms associated with cell wall thickening or defense response by callose deposition and GO terms linked to phenylpropanoid metabolic process, particularly lignin metabolic, lignin biosynthetic, and lignin catabolic processes were strongly enriched in all resistance groups (Table S3). Genes described as laccase, blue copper protein or agmatine coumaroyltransferase- 2 were strongly induced and belonged to the top $10 \%$ FRGs with the highest $\log _{2} \mathrm{FC}$ in all resistance groups (Table S4). Laccase and blue copper protein together with dirigent protein and peroxidase are known mediators of lignin polymerization [76, 77] and contribute to increased defense-induced lignification and lignin accumulation in secondary cell walls [37, 78]. Transient silencing of laccase TaLAC4 resulted in increased susceptibility leading to $F g$ spread within the wheat spike, while non-silenced NILs had thickened cell walls and higher total lignin content [37]. Lignin is one of the most persistent and difficult plant compounds to be decomposed by fungi $[79,80]$. Hence, cell wall reinforcement via lignification provides both a physical barrier against pathogen invasion and chemical protection against fungal cell wall degrading enzymes. When comparing levels of constitutive gene expression between groups, we found enrichment in the Sumai3 relative to the non-Sumai3 or SUS groups for genes related to cell wall biogenesis, plant-type secondary cell wall and associated terms (Table S6). We assume, that the secondary cell wall composition of Sumai3 lines differs from non-Sumai3 lines. This difference possibly provides preconditional defense response that may be critical for initiating a coordinated though less intense activation of defense processes in the Sumai3 compared to the non-Sumai3 groups.

Since less than $20 \%$ of the induced genes were significantly more highly expressed in Sumai3 compared to non-Sumai3 genotypes, comparably fewer GO terms were enriched for DEGs that were more highly upregulated in the Sumai3 group (Figure S2). The majority of the GO terms that were more strongly induced in the Sumai3 group belonged to terpene or terpenoid metabolic processes and terpene synthase activity and were also found in the mock treated samples (Table S6, Figure S1). For example, a gene encoding terpene synthases (TraesCS5B01G01480) was constitutively expressed and showed the second highest positive fold change $\left(\log _{2} \mathrm{FC}=\right.$ 14.7) among all DEGs between the Sumai3 and nonSumai3 groups (Table S5.2). Terpenoids constitute the most chemically and structurally diverse class of plant secondary metabolites [81], many of which have antimicrobial and antioxidant properties and are involved in plant defense signaling, ROS scavenging and reinforcement of physical barriers [82, 83]. Among metabolomic studies terpenoids were found to be the third most frequently encountered secondary metabolites that were implicated in $F g$ defense in wheat and barley [20, 83-85]. Terpenoids were positively associated with FHB resistance in the cultivar Sumai3 [72, 73]; a terpene-synthase located within the Fhb1 contig was constitutively expressed only in NILs that carried the Fhb1 resistance allele [43].

\section{Fhb1- and Qfhs.ifa-5A-specific gene expression The Fhb1 enigma - expression patterns of 96 wheat genotypes identify several Fhb1-associated candidates}

To date, four conflicting studies have reported the isolation of the gene controlling resistance to fungal spread at the Fhb1 locus. Rawat et al. [7] pinpointed a PFT gene as the major contributor of the Fhb1-mediated resistance. Su et al. [9] and Li et al. [8] suggested a deletion in the HRC gene as the responsible mutation behind the Fhb1-mediated resistance. However, the two studies disagreed on the mode of action being either the result of a recessive loss-of-function mutation [9] or a functionally novel allele actively conferring resistance [8]. Moreover, recently, Paudel et al. [86] claimed that HRC acts as suppressor of WFhb1-1, which they suggested as the 
functional component of Fhb1. WFhb1-1 is located outside the QTL interval, but the deletion in HRC inactivates its suppression and results in the 'resistant HRC allele' [86].

To further elucidate this puzzling locus, we studied gene expression of all 28 genes located in the Fhb1 contig, including PFT (AML47770) and HRC (AML47768). Thirteen of the candidates, were constitutively differentially expressed in presence or absence of Fhb1, but only a GDSL Lipase acylhydrolase (AML47772) showed constitutive- and pathogen-dependent expression patterns (Fig. 5, Table 1). Our results largely agree with a previous dense time-course study of Fhb1 candidate gene expression in two NILs [36]. We found exclusive expression in Fhb1 carrier only for a Terpene synthase (AML47767) suggesting a special role of this gene in Fhb1-mediated resistance. In contrast, HRC was expressed in many genotypes with varying resistance levels, albeit to a much weaker extent in lines without the Fhb1 resistance allele. This expression pattern is inconsistent with the proposed susceptibility factor at HRC $[9,86]$.

\section{Differential gene expression analysis reveals a stress responsive NAC secondary wall thickening-promoting factor1 (NST1) like protein as a potential candidate for Qfhs.ifa-5Ac-mediated resistance}

Centromeric and interstitial regions are known to be rich in transposable elements (TEs) [87]. This might explain the high proportion of TE-like proteins (transposon-, retrotransposon-, or retrovirus-related proteins) among DEGs identified across both QTL (Table 1). Although long considered 'junk' DNA, it is now acknowledged that TEs are important sources of binding sites for transcription factors; they can mobilize and respond to stress elicitors, alter expression of nearby genes and affect gene methylation and epigenetic adaptation [88]. TE-like protein homologs across Qfhs.ifa-5A loci were all constitutively differentially expressed. Two Gypsy-like retrotransposons were upregulated in response to DON in roots of the Sumai3 descendent CM82036 (a carrier of the resistance alleles at Qfhs.ifa-5A and Fhb1) supporting an active defense response [89].

Among all DEGs across both 5A QTL, only a stress responsive NST1-like protein (TraesCS5A01G211300LC) clearly discriminated between the resistant and susceptible haplotypes, being exclusively and constitutively highly expressed in the presence of the resistance allele at TraesCS5A01G211300LC (Table 1, Fig. 5). Genetic experiments on the model plants Arabidopsis thaliana and Medicago truncatula revealed the NAC transcription factor NST1 as a key regulator for the biosynthesis of plant-type specific secondary cell wall thickening genes in anther endothecium cells [90-94]. Anthers are considered as susceptibility factors when retained inside the floret. Qfhs.ifa-5Ac was found to simultaneously increase anther extrusion and FHB resistance [10], which is in line with the constitutive expression of NST1 in Qfhs.ifa-5Ac carriers. NST1 is required for anther dehiscence [94], however, it is unclear if NST1 affects the process of anther extrusions as well, which involves lodicule swelling for successful flower opening and filament elongation. An ectopic expression of NST1 was observed in various tissues, including filaments of stamens and the base of carpels leading to striated tracheary elementlike structures in epidermal cells [94]. After dehiscence and anther extrusion, filaments remain fully rigid for a short time. Whether NST1 induced 'tracheary' structures affect rigidity of filaments that may help push the anthers out of the floret needs further investigation.

Qfhs.ifa-5A primarily confers resistance to fungal entry and early disease development (type 1 resistance), assessed by spray or grain spawn inoculation and to a lesser extent resistance to fungal spreading within the spike (type 2 resistance), assessed by single floret inoculation [95, 96]. While constitutive gene expression is expected to be unaffected by the inoculation methods we cannot exclude that the here applied single floret inoculation method was unable to detect genes that are specifically induced by Fusarium spores germinating on the spike surface and/or hyphae entering the florets which could be causal behind type 1 resistance.

\section{Conclusions}

Infection of wheat florets by $\mathrm{Fg}$ leads to pronounced reprogramming of expression patterns in several thousands of genes in the infected tissue. Though the analyzed wheat lines were chosen to represent the full range of resistance to FHB, most of the examined wheat lines share similar defense responses. The highly resistant winter wheat lines having Sumai3 as a common ancestor were distinct from the other tested lines. Generally, higher induction of gene expression in response to $F g$ was observed in the more susceptible lines with typical stress and disease response pathways being induced. The performance of Sumai3 lines may depend on several defense mechanisms associated with cell wall biosynthesis and volatile organic compound (terpene and terpenoid) emissions. These mechanisms contributed to pre-formed and/or induced resistance during the early stages of FHB infection and thus limit fungal colonization early on.

\section{Glossary of gene sets resulted from the analyses} CEG (Constitutively Expressed Gene): gene equally expressed under both stress $(F g)$ and control conditions

FRG (Fusarium Responsive Gene): gene significantly upor down-regulated in response to $\mathrm{Fg}$ relative to control 
DEG (Differentially Expressed Gene): gene significantly up- or down-regulated between two wheat resistance groups

C-DEG (Constitutively Differentially Expressed Gene): constitutively expressed gene significantly up- or downregulated between two wheat resistance groups

FR-DEG (Fusarium Responsive Differentially Expressed Gene): gene significantly differentially expressed both in response to $\mathrm{Fg}$ relative to control and between two wheat resistance groups

\section{Supplementary Information}

The online version contains supplementary material available at https://doi. org/10.1186/s12864-021-07800-1.

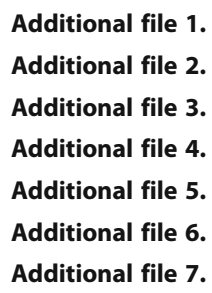

\section{Acknowledgements}

We acknowledge the excellent technical assistance in the field and greenhouse work by M. Fidesser and L. Zach. We are grateful to I. Maloko for preparing Fusarium inoculum and thank S. Zimmerl, M. Zamini, F. Jungreithmeier, B. Eshonkulov and P. Innark for assisting in RNA sampling. Many thanks to M. Zamini for RNA extraction. We acknowledge M. Lemmens for providing the Fusarium strains. We thank L. Morales for carefully reviewing the manuscript. We also like to thank Laure Duchalais from RAGT, Valerie Laurent, Ellen Goudemand-Dugué and particularly Olivier Robert*, from Florimond Desprez and for the contributed breeding lines in the framework of the FOSV project Fusatox (FSOV12010M). *deceased on February 21, 2017.

\section{Authors' contributions}

$\mathrm{CW}$ drafted the manuscript. MB and BS wrote the manuscript. TNO processed the RNA-sequencing data, supported data analyses and contributed to writing. TNU assisted in RNA-sequence mapping. CW, MB and JO analyzed the data. BS designed and supervised field and greenhouse experiments and RNA sampling. HB and KM initiated and guided through the study. All authors read and approved the final version for submission.

\section{Funding}

This study was financially supported by the Austrian Science Fund (FWF), project: SFB F3711 and Deutsche Forschungsgemeinschaft (DFG) project: LAP 3714.

\section{Availability of data and materials}

The RNA-seq raw data files generated during this study are uploaded to the the NCBI BioProject. Accession number PRJNA731024 (https://www.ncbi.nlm. nih.gov/sra/PRJNA731024). The analyzed data are available as Additional files to this article.

\section{Declarations}

\section{Ethics approval and consent to participate}

The used plant material comprises either registered Triticum aestivum cultivars or experimental lines developed by the University of Natural Resources and Life Sciences or lines obtained and used with permission from Valerie Laurent (Florimond Desprez, France) or Laure Duchalais (RAGT Semences, France) or Akos Mesterhazy (Cereal Research non-profit Szeged, Hungary). Experimental research and field studies, including the collection of plant material complies with relevant institutional, national and international guidelines and legislation.

Consent for publication

Not applicable.

\section{Competing interests}

The authors declare they have no competing interests.

\section{Author details}

'University of Natural Resources and Life Sciences, Austria, Department of Agrobiotechnology - IFA Tulln, Institute of Biotechnology in Plant Production, Konrad Lorenz Str 20, Tulln, Austria. ${ }^{2}$ Helmholtz Zentrum München, Germany, PGSB Plant Genome and Systems Biology, German Research Center for Environmental Health, Neuherberg, Germany. ${ }^{3}$ Helmholtz Zentrum München, Germany, Institut für Asthma- und Allergieprävention (IAP), Deutsches Forschungszentrum für Gesundheit und Umwelt (GmbH), Munich, Germany. ${ }^{4}$ Helmholtz Zentrum München, Germany, Research Unit Environmental Simulation (EUS) at the Institute of Biochemical Plant Pathology (BIOP), Ingolstädter Landstraße 1, 85764 Neuherberg, Germany. ${ }^{5}$ Helmholtz Zentrum München, Germany, Institute of Network Biology (INET), Ingolstädter Landstraße 1, 85764 Neuherberg, Germany. ${ }^{6}$ Helmholtz Zentrum München, Germany, Institute of Environmental Medicine UNIKA-T, Technical University and Helmholtz Zentrum München, Augsburg, Germany.

Received: 22 January 2021 Accepted: 7 June 2021

Published online: 24 June 2021

\section{References}

1. McMullen M, Bergstrom G, De Wolf E, Dill-Macky R, Hershman D, Shaner G, et al. A unified effort to fight an enemy of wheat and barley: Fusarium head blight. Plant Dis. 2012;96(12):1712-28 https://doi.org/10.1094/pdis-03-12-02 91-fe.

2. Pestka JJ. Toxicological mechanisms and potential health effects of deoxynivalenol and nivalenol. World Mycotoxin J. 2010;3(4):323-47 https:// doi.org/10.3920/wmj2010.1247.

3. Buerstmayr M, Steiner B, Buerstmayr H. Breeding for Fusarium head blight resistance in wheat_-progress and challenges. Plant Breed. 2020;139(3):42954 https://doi.org/10.1111/pbr.12797.

4. Buerstmayr H, Ban T, Anderson JA. QTL mapping and marker-assisted selection for Fusarium head blight resistance in wheat: a review. Plant Breed. 2009;128(1):1-26 https://doi.org/10.1111/j.1439-0523.2008.01550.x.

5. Ma Z, Xie Q, Li G, Jia H, Zhou J, Kong Z, et al. Germplasms, genetics and genomics for better control of disastrous wheat Fusarium head blight. Theor Appl Genet. 2020;133(5):1541-68 https://doi.org/10.1007/s00122-01903525-8.

6. Steiner B, Buerstmayr M, Michel S, Schweiger W, Lemmens M, Buerstmayr $\mathrm{H}$. Breeding strategies and advances in line selection for Fusarium head blight resistance in wheat. Trop Plant Pathol. 2017:42(3):165-74 https://doi.org/10.1 007/s40858-017-0127-7.

7. Rawat N, Pumphrey MO, Liu S, Zhang X, Tiwari VK, Ando K, et al. Wheat Fhbl encodes a chimeric lectin with agglutinin domains and a poreforming toxin-like domain conferring resistance to Fusarium head blight. Nat Genet. 2016;48(12):1576-80 https://doi.org/10.1038/ng.3706.

8. Li G, Zhou J, Jia H, Gao Z, Fan M, Luo Y, et al. Mutation of a histidine-rich calcium-binding-protein gene in wheat confers resistance to Fusarium head blight. Nat Genet. 2019;51(7):1106-12 https://doi.org/10.1038/s41588-0190426-7.

9. Su Z, Bernardo A, Tian B, Chen H, Wang S, Ma H, et al. A deletion mutation in TaHRC confers Fhb1 resistance to Fusarium head blight in wheat. Nat Genet. 2019;51(7):1099-105 https://doi.org/10.1038/s41588-019-0425-8.

10. Steiner B, Buerstmayr M, Wagner C, Danler A, Eshonkulov B, Ehn M, et al. Fine-mapping of the Fusarium head blight resistance QTL Qfhs.ifa-5A identifies two resistance QTL associated with anther extrusion. Theor Appl Genet. 2019;132(7):2039-53 https://doi.org/10.1007/s00122-019-03336-X.

11. Kang Z, Buchenauer $\mathrm{H}$. Cytology and ultrastructure of the infection of wheat spikes by Fusarium culmorum. Mycol Res. 2000;104(9):1083-93. https://doi.org/10.1017/S0953756200002495.

12. Brown NA, Urban M, van de Meene AM, Hammond-Kosack KE. The infection biology of Fusarium graminearum: defining the pathways of spikelet to 
spikelet colonisation in wheat ears. Fungal Biol. 2010;114(7):555-71 https:// doi.org/10.1016/j.funbio.2010.04.006

13. Bönnighausen J, Schauer N, Schäfer W, Bormann J. Metabolic profiling of wheat rachis node infection by Fusarium graminearum - decoding deoxynivalenol-dependent susceptibility. New Phytol. 2019;221(1):459-69 https://doi.org/10.1111/nph.15377.

14. Desmond OJ, Manners JM, Stephens AE, Maclean DJ, Schenk PM, Gardiner DM, et al. The Fusarium mycotoxin deoxynivalenol elicits hydrogen peroxide production, programmed cell death and defence responses in wheat. Mol Plant Pathol. 2008;9(4):435-45 https://doi.org/10.1111/j.1364-3 703.2008.00475.x.

15. de Wit P. Visions \& reflections (minireview) - how plants recognize pathogens and defend themselves. Cell Mol Life Sci. 2007;64(21):2726-32 https://doi.org/10.1007/s00018-007-7284-7.

16. Kazan K, Gardiner DM. Transcriptomics of cereal-Fusarium graminearum interactions: what we have learned so far. Mol Plant Pathol. 2018;19(3):76478 https://doi.org/10.1111/mpp.12561

17. Wang L, Li Q, Liu Z, Surendra A, Pan Y, Li Y, et al. Integrated transcriptome and hormone profiling highlight the role of multiple phytohormone pathways in wheat resistance against Fusarium head blight. PLoS One. 2018;13(11):e0207036 https://doi.org/10.1371/journal.pone.0207036.

18. Atanasova-Penichon V, Barreau C, Richard-Forget F. Antioxidant secondary metabolites in cereals: potential involvement in resistance to Fusarium and mycotoxin accumulation. Front Microbiol. 2016;7:7(566). https://doi.org/1 0.3389/fmicb.2016.00566.

19. Gottwald S, Samans B, Lück S, Friedt W. Jasmonate and ethylene dependent defence gene expression and suppression of fungal virulence factors: two essential mechanisms of Fusarium head blight resistance in wheat? BMC Genomics. 2012;13(1):369 https://doi.org/10.1186/1471-2164-13-369.

20. Dhokane D, Karre S, Kushalappa AC, McCartney C. Integrated metabolotranscriptomics reveals Fusarium head blight candidate resistance genes in wheat QTL-Fhb2. PLoS One. 2016;11(5):e0155851 https://doi.org/10.1371/ journal.pone.0155851.

21. Xiao J, Jin X, Jia X, Wang H, Cao A, Zhao W, et al. Transcriptome-based discovery of pathways and genes related to resistance against Fusarium head blight in wheat landrace Wangshuibai. BMC Genomics. 2013;14(1):197. https://doi.org/10.1186/1471-2164-14-197.

22. Steiner $B$, Kurz $H$, Lemmens $M$, Buerstmayr $H$. Differential gene expression of related wheat lines with contrasting levels of head blight resistance after Fusarium graminearum inoculation. Theor Appl Genet. 2009;118(4):753-64 https://doi.org/10.1007/s00122-008-0935-8.

23. Sari E, Cabral AL, Polley B, Tan YF, Hsueh E, Konkin DJ, et al. Weighted gene co-expression network analysis unveils gene networks associated with the Fusarium head blight resistance in tetraploid wheat. BMC Genomics. 2019; 20. https://doi.org/10.1186/s12864-019-6161-8(1):925.

24. Nussbaumer T, Warth B, Sharma S, Ametz C, Bueschl C, Parich A, et al. Joint transcriptomic and metabolomic analyses reveal changes in the primary metabolism and imbalances in the subgenome orchestration in the bread wheat molecular response to Fusarium graminearum. G3. 2015;5(12):2579-92 https://doi.org/10.1534/g3.115.021550.

25. Erayman M, Turktas M, Akdogan G, Gurkok T, Inal B, Ishakoglu E, et al. Transcriptome analysis of wheat inoculated with Fusarium graminearum. Front Plant Sci. 2015;6(867) https://doi.org/10.3389/fpls.2015.00867.

26. Biselli C, Bagnaresi P, Faccioli P, Hu X, Balcerzak M, Mattera MG, et al. Comparative transcriptome profiles of near-isogenic hexaploid wheat lines differing for effective alleles at the 2DL FHB resistance QTL. Front Plant Sci. 2018;9(37):37 https://doi.org/10.3389/fpls.2018.00037.

27. Ding L, Xu H, Yi H, Yang L, Kong Z, Zhang L, et al. Resistance to hemibiotrophic $F$. graminearum infection is associated with coordinated and ordered expression of diverse defense signaling pathways. PLOS ONE. 2011; 6(4):e19008 https://doi.org/10.1371/journal.pone.0019008.

28. Pan Y, Liu Z, Rocheleau H, Fauteux F, Wang Y, McCartney C, et al. Transcriptome dynamics associated with resistance and susceptibility against fusarium head blight in four wheat genotypes. BMC Genomics. 2018;19(1):642 https://doi.org/10.1186/s12864-018-5012-3.

29. Brauer EK, Rocheleau H, Balcerzak M, Pan Y, Fauteux F, Liu Z, et al. Transcriptional and hormonal profiling of Fusarium graminearum-infected wheat reveals an association between auxin and susceptibility. Physiol Mol Plant Pathol. 2019;107:33-9 https://doi.org/10.1016/j.pmpp.2019.04.006.

30. Foroud NA, Ouellet T, Laroche A, Oosterveen B, Jordan MC, Ellis BE, et al. Differential transcriptome analyses of three wheat genotypes reveal different host response pathways associated with Fusarium head blight and trichothecene resistance. Plant Pathol. 2012;61(2):296-314 https://doi.org/1 0.1111/j.1365-3059.2011.02512.x.

31. Gilsinger J, Kong L, Shen $\mathrm{X}, \mathrm{Ohm} \mathrm{H}$. DNA markers associated with low Fusarium head blight incidence and narrow flower opening in wheat. Theor Appl Genet. 2005;1 10(7):1218-25 https://doi.org/10.1007/s00122-005-1953-4.

32. Kubo K, Kawada N, Fujita M, Hatta K, Oda S, Nakajima T. Effect of cleistogamy on Fusarium head blight resistance in wheat. Breed Sci. 2010; 60(4):405-11 https://doi.org/10.1270/jsbbs.60.405.

33. Jia HY, Cho SH, Muehlbauer GJ. Transcriptome analysis of a wheat nearisogenic line pair carrying Fusarium head blight-resistant and -susceptible alleles. Mol Plant-Microbe Interact. 2009;22(11):1366-78 https://doi.org/10.1 094/mpmi-22-11-1366.

34. Kugler KG, Siegwart G, Nussbaumer T, Ametz C, Spannagl M, Steiner B, et al. Quantitative trait loci-dependent analysis of a gene co-expression network associated with Fusarium head blight resistance in bread wheat (Triticum aestivum L. ). BMC Genomics. 2013;14(1):14. https://doi.org/10.1186/1471-2164-14-728.

35. Samad-Zamini M, Schweiger W, Nussbaumer T, Mayer KFX, Buerstmayr $H$. Time-course expression QTL-atlas of the global transcriptional response of wheat to Fusarium graminearum. Plant Biotechnol J. 2017;15(11):1453-64 https://doi.org/10.1111/pbi.12729.

36. Schweiger W, Steiner B, Ametz C, Siegwart G, Wiesenberger G, Berthiller F, et al. Transcriptomic characterization of two major Fusarium resistance quantitative trait loci (QTLs), Fhb1 and Qfhs.ifa-5A, identifies novel candidate genes. Mol Plant Pathol. 2013;14(8):772-85 https://doi.org/10.1111/mpp.12048.

37. Soni N, Hegde N, Dhariwal A, Kushalappa AC. Role of laccase gene in wheat NILS differing at QTL-Fhb1 for resistance against Fusarium head blight. Plant Sci. 2020; 298:110574 https://doi.org/10.1016/.jplantsci.2020.110574.

38. Michel S, Wagner C, Nosenko T, Steiner B, Samad-Zamini M, Buerstmayr M, et al. Merging genomics and transcriptomics for predicting Fusarium head blight resistance in wheat. Genes (Basel). 2021;12(1):114 https://doi.org/10.33 90/genes12010114.

39. Bolger AM, Lohse M, Usadel B. Trimmomatic: a flexible trimmer for Illumina sequence data. Bioinformatics. 2014;30(15):2114-20 https://doi.org/10.1093/ bioinformatics/btu170.

40. Andrews S. FASTQC. A quality control tool for high throughput sequence data. 2010. Available online at: http://www.bioinformatics.babraham.ac.uk/ projects/fastqc.

41. Kim D, Langmead B, Salzberg SL. HISAT: a fast spliced aligner with low memory requirements. Nat Methods. 2015;12(4):357-60 https://doi.org/10.1 038/nmeth.3317.

42. International Wheat Genome Sequencing $C$, investigators IRp, Appels $R_{\text {, }}$ Eversole K, Feuillet C, Keller B, Rogers J, et al. Shifting the limits in wheat research and breeding using a fully annotated reference genome. Science. 2018;361(6403):eaar7191 https://doi.org/10.1126/ science.aar7191.

43. Schweiger W, Steiner B, Vautrin S, Nussbaumer T, Siegwart G, Zamini M, et al. Suppressed recombination and unique candidate genes in the divergent haplotype encoding Fhb1, a major Fusarium head blight resistance locus in wheat. Theor Appl Genet. 2016;129(8):1607-23 https:// doi.org/10.1007/s00122-016-2727-x.

44. Liao Y, Smyth GK, Shi W. featureCounts: an efficient general purpose program for assigning sequence reads to genomic features. Bioinformatics. 2014;30(7):923-30 https://doi.org/10.1093/bioinformatics/btt656.

45. Li H, Handsaker B, Wysoker A, Fennell T, Ruan J, Homer N, et al. The sequence alignment/map format and SAMtools. Bioinformatics. 2009;25(16): 2078-9 https://doi.org/10.1093/bioinformatics/btp352.

46. Love MI, Huber W, Anders S. Moderated estimation of fold change and dispersion for RNA-seq data with DESeq2. Genome Biol. 2014;15(12):550 https://doi.org/10.1186/s13059-014-0550-8.

47. Falcon S, Gentleman R. Using GOstats to test gene lists for $\mathrm{GO}$ term association. Bioinformatics. 2007;23(2):257-8 https://doi.org/10.1093/ bioinformatics/bt|567.

48. Fabre F, Vignassa M, Urbach S, Langin T, Bonhomme L. Time-resolved dissection of the molecular crosstalk driving Fusarium head blight in wheat provides new insights into host susceptibility determinism. Plant Cell Environ. 2019;42(7):2291-308 https://doi.org/10.1111/pce.13549.

49. Chowdhury S, Basu A, Kundu S. Biotrophy-necrotrophy switch in pathogen evoke differential response in resistant and susceptible sesame involving multiple signaling pathways at different phases. Sci Rep. 2017;7(1):17251 https://doi.org/10.1038/s41598-017-17248-7. 
50. Romeis T. Protein kinases in the plant defence response. Curr Opin Plant Biol. 2001;4(5):407-14 https://doi.org/10.1016/s1369-5266(00)00193-x.

51. Jones JD, Dangl JL. The plant immune system. Nature. 2006;444(7117):323-9 https://doi.org/10.1038/nature05286.

52. Tang D, Wang G, Zhou J-M. Receptor kinases in plant-pathogen interactions: more than pattern recognition. Plant Cell. 2017;29(4):618-37 https://doi.org/10.1105/tpc.16.00891.

53. Tuteja N, Mahajan S. Calcium signaling network in plants: an overview. Plant Signal Behav. 2007;2(2):79-85 https://doi.org/10.4161/psb.2.2.4176.

54. Ku Y-S, Sintaha M, Cheung M-Y, Lam H-M. Plant hormone signaling crosstalks between biotic and abiotic stress responses. Int J Mol Sci. 2018; 19(10):3206 https://doi.org/10.3390/ijms19103206.

55. Ma W, Berkowitz GA. The grateful dead: calcium and cell death in plant innate immunity. Cell Microbiol. 2007;9(11):2571-85 https://doi.org/10.1111/ j.1462-5822.2007.01031.x

56. O'Brien JA, Daudi A, Butt VS, Paul Bolwell G. Reactive oxygen species and their role in plant defence and cell wall metabolism. Planta. 2012;236(3): 765-79 https://doi.org/10.1007/s00425-012-1696-9.

57. Apel K, Hirt H. Reactive oxygen species: metabolism, oxidative stress, and signal transduction. Annu Rev Plant Biol. 2004;55(1):373-99 https://doi.org/1 0.1146/annurev.arplant.55.031903.141701.

58. Barna B, Fodor J, Harrach BD, Pogány M, Király Z. The Janus face of reactive oxygen species in resistance and susceptibility of plants to necrotrophic and biotrophic pathogens. Plant Physiol Biochem. 2012;59:37-43 https://doi. org/10.1016/j.plaphy.2012.01.014.

59. Durrant WE, Dong X. Systemic acquired resistance. Annu Rev Phytopathol. 2004;42(1):185-209 https://doi.org/10.1146/annurev.phyto.42.040803.140421.

60. Foyer $\mathrm{CH}$, Noctor $\mathrm{G}$. Redox homeostasis and antioxidant signaling: a metabolic interface between stress perception and physiological responses. Plant Cell. 2005;17(7):1866-75 https://doi.org/10.1105/tpc.105.033589.

61. Khaledi N, Taheri P, Falahati-Rastegar M. Reactive oxygen species and antioxidant system responses in wheat cultivars during interaction with Fusarium species. Australas Plant Pathol. 2016;45(6):653-70 https://doi.org/1 0.1007/s13313-016-0455-y.

62. Gullner G, Komives T, Király L, Schröder P. Glutathione s-transferase enzymes in plant-pathogen interactions. Front Plant Sci. 2018;871:1836.

63. Edwards R, Dixon DP, Walbot V. Plant glutathione S-transferases: enzymes with multiple functions in sickness and in health. Trends Plant Sci. 2000;5(5): 193-8 https://doi.org/10.1016/s1360-1385(00)01601-0.

64. Gardiner SA, Boddu J, Berthiller F, Hametner C, Stupar RM, Adam G, et al. Transcriptome analysis of the barley-deoxynivalenol interaction: evidence for a role of glutathione in deoxynivalenol detoxification. Mol Plant-Microbe Interact. 2010;23(7):962-76 https://doi.org/10.1094/mpmi-23-7-0962.

65. Wang H, Sun S, Ge W, Zhao L, Hou B, Wang K, et al. Horizontal gene transfer of Fhb7 from fungus underlies Fusarium head blight resistance in wheat. Science. 2020;368(6493):eaba5435 https://doi.org/10.1126/science.aba 5435.

66. Gadaleta A, Colasuonno P, Giove SL, Blanco A, Giancaspro A. Map-based cloning of QFhb.mgb-2A identifies a WAK2 gene responsible for Fusarium Head Blight resistance in wheat. Sci Rep. 2019;9(1):6929 https://doi.org/10.1 038/s41598-019-43334-z.

67. Foroud NA, Baines D, Gagkaeva TY, Thakor N, Badea A, Steiner B, et al. Trichothecenes in cereal grains - an update. Toxins (Basel). 2019;11(11):48 https://doi.org/10.3390/toxins11110634.

68. Lemmens M, Scholz U, Berthiller F, Dall'Asta C, Koutnik A, Schuhmacher R, et al. The ability to detoxify the mycotoxin deoxynivalenol colocalizes with a major quantitative trait locus for Fusarium head blight resistance in wheat. Mol Plant-Microbe Interact. 2005;18(12):1318-24 https://doi.org/10.1094/ mpmi-18-1318.

69. Walter S, Doohan F. Transcript profiling of the phytotoxic response of wheat to the Fusarium mycotoxin deoxynivalenol. Mycotoxin Res. 2011;27(3):22130 https://doi.org/10.1007/s12550-011-0099-2.

70. Gunupuru LR, Perochon A, Doohan FM. Deoxynivalenol resistance as a component of FHB resistance. Trop Plant Pathol. 2017;42(3):175-83 https:// doi.org/10.1007/s40858-017-0147-3.

71. Wang G, Hou W, Zhang L, Wu H, Zhao L, Du X, et al. Functional analysis of a wheat pleiotropic drug resistance gene involved in Fusarium head blight resistance. J Integr Agric. 2016;15(10):2215-27 https://doi.org/10.1016/S2 095-3119(16)61362-X.

72. Gunnaiah R, Kushalappa AC. Metabolomics deciphers the host resistance mechanisms in wheat cultivar Sumai-3, against trichothecene producing and non-producing isolates of Fusarium graminearum. Plant Physiol Biochem. 2014;83:40-50 https://doi.org/10.1016/j.plaphy.2014.07.002.

73. Gunnaiah R, Kushalappa A, Duggavathi R, Fox S, Somers DJ. Integrated metabolo-proteomic approach to decipher the mechanisms by which wheat QTL (Fhb1) contributes to resistance against Fusarium graminearum PLoS One. 2012;7(7):e40695. https://doi.org/10.1371/journal.pone.0040695.

74. Lahlali R, Kumar S, Wang L, Forseille L, Sylvain NJ, Korbas M, et al. Cell wall biomolecular composition plays a potential role in the host type II resistance to Fusarium head blight in wheat. Front Microbiol. 2016;7. https:// doi.org/10.3389/fmicb.2016.00910.

75. Kang Z, Buchenauer H. Ultrastructural and immunocytochemical investigation of pathogen development and host responses in resistant and susceptible wheat spikes infected by Fusarium culmorum. Physiol Mol Plant Pathol. 2000;57(6):255-68 https://doi.org/10.1006/pmpp.2000.0305.

76. Weiss R, Guebitz GM, Pellis A, Nyanhongo GS. Harnessing the power of enzymes for tailoring and valorizing lignin. Trends Biotechnol. 2020;38(11): 1215-31 https://doi.org/10.1016/j.tibtech.2020.03.010.

77. Berthet S, Thevenin J, Baratiny D, Demont-Caulet N, Debeaujon I, Bidzinski P, et al. Role of plant laccases in lignin polymerization. In: Jouann L, Lapierre C, editors. Lignins: Biosynthesis, Biodegradation and Bioengineering, vol. 61. San Diego: Elsevier Academic Press Inc; 2012. p. 145-67.

78. Berthet S, Demont-Caulet N, Pollet B, Bidzinski P, Cézard L, Le Bris P, et al. Disruption of LACCASE4 and 17 results in tissue-specific alterations to lignification of Arabidopsis thaliana stems. Plant Cell. 2011;23(3):1124-37 https://doi.org/10.1105/tpc.110.082792.

79. Blanchette RA. Delignification by wood-decay fungi. Annu Rev Phytopathol. 1991;29(1):381-403 https://doi.org/10.1146/annurev.py.29.090191.002121.

80. Walter S, Nicholson P, Doohan FM. Action and reaction of host and pathogen during Fusarium head blight disease. New Phytol. 2010;185(1):5466 https://doi.org/10.1111/j.1469-8137.2009.03041.x.

81. Singh B, Sharma RA, et al. 3 Biotech. 2015;5(2):129-51 https://doi.org/10.1 007/s13205-014-0220-2.

82. Hammerbacher A, Coutinho TA, Gershenzon J. Roles of plant volatiles in defence against microbial pathogens and microbial exploitation of volatiles. Plant Cell Environ. 2019;42(10):2827-43 https://doi.org/10.1111/ pce.13602.

83. Gauthier L, Atanasova-Penichon V, Chereau S, Richard-Forget F. Metabolomics to decipher the chemical defense of cereals against Fusarium graminearum and deoxynivalenol accumulation. Int J Mol Sci. 2015;16(10): 24839-72 https://doi.org/10.3390/ijms161024839.

84. Bollina V, Kushalappa AC, Choo TM, Dion Y, Rioux S. Identification of metabolites related to mechanisms of resistance in barley against Fusarium graminearum, based on mass spectrometry. Plant Mol Biol. 2011;77(4-5): 355-70 https://doi.org/10.1007/s11103-011-9815-8.

85. Chamarthi SK, Kumar K, Gunnaiah R, Kushalappa AC, Dion Y, Choo TM Identification of fusarium head blight resistance related metabolites specific to doubled-haploid lines in barley. Eur J Plant Pathol. 2014;138(1):67-78 https://doi.org/10.1007/s10658-013-0302-8.

86. Paudel B, Zhuang Y, Galla A, Dahal S, Qiu Y, Ma A, et al. WFhb1-1 plays an important role in resistance against Fusarium head blight in wheat. Sci Rep. 2020;10(1):7794 https://doi.org/10.1038/s41598-020-64777-9.

87. Bariah I, Keidar-Friedman D, Kashkush K. Where the wild things are: transposable elements as drivers of structural and functional variations in the wheat genome. Front Plant Sci. 2020;11(1477) https://doi.org/10.3389/ fpls.2020.585515.

88. Galindo-González L, Sarmiento F, Quimbaya MA. Shaping plant adaptability, genome structure and gene expression through transposable element epigenetic control: focus on methylation. Agronomy. 2018;8(9):180. https:// doi.org/10.3390/agronomy8090180.

89. Ansari Kl, Walter S, Brennan JM, Lemmens M, Kessans S, McGahern A, et al. Retrotransposon and gene activation in wheat in response to mycotoxigenic and non-mycotoxigenic-associated Fusarium stress. Theor Appl Genet. 2007;114(5):927-37 https://doi.org/10.1007/s00122-006-0490-0.

90. Mitsuda N, Iwase A, Yamamoto H, Yoshida M, Seki M, Shinozaki K, et al. NAC transcription factors, NST1 and NST3, are key regulators of the formation of secondary walls in woody tissues of Arabidopsis. Plant Cell. 2007;19(1):27080 https://doi.org/10.1105/tpc.106.047043.

91. Zhang Q, Luo F, Zhong Y, He J, Li L. Modulation of NAC transcription factor NST1 activity by XYLEM NAC DOMAIN1 regulates secondary cell wall formation in Arabidopsis. J Exp Bot. 2020;71(4):1449-58 https://doi.org/10.1 093/jxb/erz513. 
92. Taylor-Teeples M, Lin L, de Lucas M, Turco G, Toal TW, Gaudinier A, et al. An Arabidopsis gene regulatory network for secondary cell wall synthesis. Nature. 2015;517(7536):571-5 https://doi.org/10.1038/nature14099.

93. Zhao Q, Gallego-Giraldo L, Wang H, Zeng Y, Ding S-Y, Chen F, et al. An NAC transcription factor orchestrates multiple features of cell wall development in Medicago truncatula. Plant J. 2010;63(1):100-14 https://doi.org/10.1111/ j.1365-313X.2010.04223.X.

94. Mitsuda N, Seki M, Shinozaki K, Ohme-Takagi M. The NAC transcription factors NST1 and NST2 of Arabidopsis regulate secondary wall thickenings and are required for anther dehiscence. Plant Cell. 2005;17(11):2993-3006 https://doi.org/10.1105/tpc.105.036004.

95. Buerstmayr H, Lemmens M, Hartl L, Doldi L, Steiner B, Stierschneider M, et al. Molecular mapping of QTLS for Fusarium head blight resistance in spring wheat. I. Resistance to fungal spread (type II resistance). Theor Appl Genet. 2002;104(1):84-91 https://doi.org/10.1007/s001220200009.

96. Buerstmayr H, Steiner B, Hartl L, Griesser M, Angerer N, Lengauer D, et al. Molecular mapping of QTLs for Fusarium head blight resistance in spring wheat. II. Resistance to fungal penetration and spread. Theor Appl Genet. 2003;107(3):503-8 https://doi.org/10.1007/s00122-003-1272-6.

\section{Publisher's Note}

Springer Nature remains neutral with regard to jurisdictional claims in published maps and institutional affiliations.

Ready to submit your research? Choose BMC and benefit from:

- fast, convenient online submission

- thorough peer review by experienced researchers in your field

- rapid publication on acceptance

- support for research data, including large and complex data types

- gold Open Access which fosters wider collaboration and increased citations

- maximum visibility for your research: over $100 \mathrm{M}$ website views per year

At $\mathrm{BMC}$, research is always in progress.

Learn more biomedcentral.com/submissions 